\title{
FONTES DE CONTAMINAÇÃO E CONTÁGIO DE Prototheca zopfii EM PROPRIEDADE LEITEIRA
}

(Sources of contamination and contagion Prototheca zopfii in dairy property)

Paulo Fernandes Marcusso, Sylvia Marquart Fontes Novo, Silas Fernandes Eto, Dayanne Carla Fernandes, Erika Cosendey Toledo de Mello Peixoto, Rogério Salvado

*Correspondência: paulomarcusso@gmail.com

RESUMO: O trabalho teve como objetivo foi determinar fontes de contaminação e contágio de Prototheca zopfii em propriedade leiteira situada na cidade de Ribeirão do Pinhal, Estado do Paraná. Material e Métodos: foram coletadas 33 amostras com suabe estéril de diferentes locais relacionados à produção leiteira. As amostras foram imersas em meio líquido de infusão de cérebro e coração (BHI) e incubadas sob aerofilia em estufa à $37^{\circ} \mathrm{C}$ por 24 horas. Após esse período foram repicadas em meio sólido de $\mathrm{BHI}$ adicionado a sangue ovino desfibrinado e novamente incubados nas mesmas condições por 48 a 96 horas. Também foram coletadas amostras de leite de dois animais suspeitos e foram processadas conforme método recomendado pelo National Mastitis Council. As análises positivas no crescimento microbiano, foram identificadas segundo as características macro e microscópicas bioquímicas e tintoriais. Resultados: a alga Prototheca zopfii apresentou-se em $31,4 \%$ das amostras, inclusive nas mãos dos responsáveis pela ordenha. Conclusão: esta pesquisa demonstra a importância de adotar manejo profilático para garantir higidez dos rebanhos e dos funcionários das propriedades leiteiras.

Palavras-chave: mastite; prototecose; zoonose; leite; ambiente

ABSTRACT: The study aimed to determine the sources of contamination and contagion Prototheca zopfii in dairy property located in the city of Ribeirão do Pinhal, State of Paraná. Material and Methods: was collected 33 swabs samples with sterile in different local related to milk production. The samples were immersed in liquid medium of brain heart infusion (BHI) and incubated under aerofilia in oven at $37^{\circ} \mathrm{C}$ for 24 hours. After this period were subcultured in $\mathrm{BHI}$ solid medium added to defibrinated sheep blood and incubated again under the same conditions for 48 to 96 hours. Two milk samples suspected animals were also collected and processed as recommended by the National Mastitis Council method (1996). Positive analysis on microbial growth, were identified by characteristics macro and microscopic biochemical and dyeing. Results: Prototheca zopfii appeared in $31.4 \%$ of samples, even in the hands of those responsible for milking. Conclusion: This study demonstrates the importance of adopting prophylactic management to ensure the sound of herds and employees of dairy farms.

Key Words: mastitis; protothecosis; zoonosis; milk; environment 
Fontes de contaminação e contágio de prototheca zopfii em propriedade leiteira

\section{INTRODUÇÃO}

A produção de leite no Brasil em 2011 foi de 32,2 bilhões de litros (IBGE, 2011). A mastite bovina caracterizada por uma inflamação da glândula mamária em resposta a uma infecção, que pode ser causada por algas (Tozzeti et al., 2008), causando significativas perdas econômicas (Heikkilä et al., 2012).

Especialmente, em locais úmidos encontra-se o agente causador de uma doença, denominada Prototecose (Pore et al., 1983). Este gênero contém cinco espécies, Prototheca zopfii, $P$. moriformis, $P$. wickerhamii, $P$. ulmea e $P$. stagnora (Pore, 1998).

A mastite clínica e subclínica provocada por Prototheca zopfii em bovinos tem demonstrado elevação do número de relatos há algumas décadas, desde a primeira descrição feita por Lerche (1952) na Alemanha. No Brasil, já foi descrita em Minas Gerais (Costa et al., 1998a), São Paulo e Paraná (Camargo e Fischman, 1981), Santa Catarina (Vaz et al., 2005) e Goiás (Bueno et al., 2006), sendo considerada, portanto, uma doença emergente (Yamamura, 2006).

Além de ser considerada uma zoonose, a mastite bovina causada por Prototheca zopfii tem importância econômica, social e em saúde pública, por causar infecção persistente, refratária à terapêutica tradicional, e reduzir significativamente a produção leiteira (Yamamura, 2006).

As algas do gênero Prototheca, $P$. zopfii e $P$. wickerhamii podem causar infecção oportunista pouco frequente, sob as formas localizada ou sistêmica, denominada prototecose, no homem (Tang et al., 1995; Monopoli et al., 1995), nos animais domésticos (Tanyiama et al., 1994) e silvestres (Frese e Gedek, 1968). A prototecose nos animais foi descrita em várias espécies domésticas e silvestres: bovinos, cães, gatos, cervos e salmão. A infecção nos animais inferiores apresenta uma forma mais severa, com caráter sistêmico ou localizado. Ela já foi relatada em diversos países sob forma de surtos ou de casos isolados (Dion, 1982; Hodges et al., 1985; Spalton, 1985; Costa et al., 1992; Langoni et al., 1992; Almeraya, 1994; Costa et al.,1995; Costa et al., 1996; Costa et al., 1998b; Tenhagen et al., 1999; Jánosl et al.,2001).

O trabalho teve por objetivo em determinar as possíveis fontes de contaminação e contágio de Prototheca zopfii em uma propriedade leiteira.

\section{MATERIAL E MÉTODOS}

Foram realizadas coletas, de 33 suabes de diferentes locais, de uma propriedade comercial leiteira, localizada no município de Ribeirão do Pinhal-PR, latitude: $23^{\circ} 24^{\prime} 27^{\prime \prime} \mathrm{S}$ e longitude: $50^{\circ} 21^{\prime}$ 24" W (IBGE, 2002).

Os suabes foram imersos, individualmente, em meio líquido de infusão de cérebro e coração (BHI) e refrigerados em gelo artificial, e transportados em recipientes isotérmicos até o Laboratório.

As análises foram realizadas no Laboratório de Microbiologia Veterinária da Universidade Estadual do Norte do Paraná, Campus Luiz Meneghel (UENP/CLM), Bandeirantes-PR.

No laboratório os suabes foram incubados sob aerofilia em estufa à $37^{\circ} \mathrm{C}$ por 24 horas. Após esse período as amostras foram repicadas através de alça de platina em meio sólido de $\mathrm{BHI}$ adicionado $5 \%$ de sangue de ovino desfibrinado e incubados nas mesmas condições citadas anteriormente por 48 a 96 horas.

Também foram coletadas duas amostras de leite de animais suspeitos, de cada quarto mamário (Bueno et al., 2003). E realizou-se o processamento dessas amostras conforme o método recomendado pelo National Mastitis Council (1996). 
Posteriormente, as colônias que apresentavam características compatíveis com a $P$. zopfii foram submetidas às provas bioquímicas, tintoriais, macro e microscópicas para a identificação (Jánosl et al., 2001; Brito e Brito, 1999; Pore, 1998; Langoni et al., 1995).

\section{RESULTADOS E DISCUSSÃO}

Das 35 amostras coletadas, foram isoladas Prototheca zopfii de $11(31,4 \%)$, sendo elas; nos tanques de água e cocho do confinamento, na saída do resfriador, na sala de espera, em um conjunto de teteiras da sala de ordenha, de dois animais em lactação, das mãos do funcionário responsável pela sala de ordenha e mãos do funcionário responsável pelo trato pós-ordenha.

A Prototheca spp. é ubiquitária e, portanto, pode ser encontrada no solo, na água, em fezes de diferentes espécies animais e equipamento de ordenha (Melville, 1995). Ao ser isolada em locais de alimentação dos animais, como no tanque de água e no cocho, demonstra que as condições do manejo e piquetes, os quais permaneciam os animais, favoreciam a multiplicação do patógeno, tornando-se importante fonte de contaminação ambiental.

Segundo Leimann et al. (2004) no homem a prototecose pode se manifestar sob várias formas clínicas, localizadas ou sistêmicas, sendo considerada uma zoonose. Além disso a resistência do microrganismo à pasteurização pode aumentar seu potencial zoonótico (Melville et al.,1999).

$\mathrm{O}$ isolamento ocorrido no processo de ordenha indica que os procedimentos utilizados na ordenha contribuíram para a disseminação do patógeno, uma vez que foi isolado em um dos conjuntos da ordenhadeira mecânica, o qual é utilizado por outros animais.

Prototecose é uma doença pouco conhecida e pode ser confundida com outras enfermidades, especialmente com infecções fúngicas, portanto é raramente diagnosticada (Carneiro et al., 2007). Todavia pode representar uma doença emergente e de extrema importância na bovinocultura leiteira brasileira.

A P. zopfii foi isolada a partir do leite de dois animais em lactação, os quais apresentavam mastite clínica com sinais de aumento da temperatura local, dor à palpação e leite com alto acúmulo de grumos. Historicamente foram realizadas diversas tentativas de tratamento intramamário com antimicrobianos, antifúngicos e até antihelmínticos, todavia nunca foram bemsucedidas, por isso muitos autores têm confirmado que o tratamento de vacas leiteiras acometidas com mastite não altera o curso da doença (Lagneau, 1996).

Com a impossibilidade de cura por meio da utilização dos recursos terapêuticos consagrados na atualidade resultou em recomendação internacional para que as vacas leiteiras com mastite por Prototheca spp. sejam segregadas e rapidamente removidas do rebanho com a finalidade de prevenir uma possível disseminação do agente infeccioso (Kirk, 1991).

Por se tratar de um agente zoonótico, foi realizada a coleta de suabes das mãos de funcionários que apresentavam contato direto com 0 processo de ordenha, nos dois casos a $P$. zopfii foi isolada. Os sinais clínicos encontrados nos funcionários foram lesões cutâneas eritematosas que não cicatrizavam, características compatíveis com os sinais descritos por Dipersio (2001), Follador et al. (2001) e Thiele e Bergmann (2002). Sugerindo que pessoas que apresentam íntimo contato com o processo de ordenha e com os animais podem se transformar em potenciais fontes de infecção, além de estarem expostos a microrganismos altamente patogênicos. 
Fontes de contaminação e contágio de prototheca zopfii em propriedade leiteira

\section{CONCLUSÃO}

O isolamento de Prototheca zopfii foi positivo em vários locais dentro da propriedade leiteira, tanto no ambiente externo, quanto na sala de ordenha, demonstrando a importância de adotar boas prática de manejo e medidas profiláticas, visando evitar a infecção e/ou disseminação do patógeno na propriedade, garantindo a saúde dos animais e dos funcionários.

\section{REFERÊNCIAS}

ALMERAYA, A. P. Aislamento de Prototheca em un brote de mastitis bovina. Veterinaria México, [S.I.], v. 25, n.1, p. 65-67, 1994.

BRITO, M. A. V. P.; BRITO, J. R. F. Diagnóstico microbiológico da mastite. Juiz de Fora: Embrapa Gado de Leite, p. 26, 1999.

BUENO, V. F. F.; NEVES, R. B. S.; THOMAZ, L.W.; MESQUITA, A. J.; OLIVEIRA, A. N.; AKINAGA, M. H. Utilização de amostra de leite composta na identificação de Prototheca zopfii. In: CONGRESSO BRASILEIRO DE MICROBIOLOGIA, p. 22, 2003, Florianópolis. Anais eletrônicos ... [CD-ROM], Florianópolis: SBM, 2003.

BUENO, V. F. F., MESQUITA, A. J., NEVES, R. B. S. et al. Epidemiological and clinical aspects of the first outbreak of bovine mastitis caused by Prototheca zopfii in Goiás State, Brazil. Mycopathologia, v. 161, p. 141-145, 2006.

CAMARGO, Z. P.; FISCHMAN, O. Isolation of Prototheca from water samples from Southern Brazil Organisms of uncertain taxonomic position. Rickia, v. 9, p. 55-59, 1981.

CARNEIRO, F. P.; MORAES, M. A. P., REBÊLO, A. M. G. et al. 2007. Prototecose cutânea: relato de caso. Revista da Sociedade Brasileira de Medicina Tropical, v. 40, n. 4, p. 466-468.

COSTA, E.; SHARUK, D. A.; TAMASO, E.; CARCIOFI, A. MELVILLE, P. A; PÂNTANO, T.; PRADA, M. S. Contribuição para o estudo da etiologia da mastite infecciosa bovina. In: CONGRESSO BRASILEIRO DE MEDICINA VETERINÁRIA, 22., 1992, Curitiba, Anais..., Curitiba, 1992.

COSTA, E. O; BENITES, N. R.; MELVILLE, P. A et al. Estudo etiológico da mastite clínica bovina.
Revista Brasileira de Medicina Veterinária, São Paulo, v.17, n.4, p. 156-158, 1995.

COSTA, E. O.; RIBEIRO, A. R.; WATANABE, E. T. et al. An increased incidence of mastitis caused by Prototheca species and Nocardia species on a farm in São Paulo, Brazil. Veterinary Research Communications, Netherlands, v.20, p.237-241, 1996.

COSTA, E.O., MELVILLE, P. A., RIBEIRO, A. R et al. Relato de um caso de consumo de queijo fresco contaminado com Prototheca spp. Revista NAPGAMA, v. 1, p. 9-19, 1998a.

COSTA, E. O : RIBEIRO, A. R : WATANABE, E. $T$. et al. Infectious bovine mastitis caused by environmental organisms. Journal of Veterinary Medicine, Berlin, v.45, p.65-71, 1998b.

DION, W. M. Bovine mastitis due to Prototheca zopfii II. Canadian Veterinary Journal, Ontario, v.23, p.272-275, 1982.

DIPERSIO J.R. Prototheca and protothecosis. Clin. Microbiol. Newsletter, v. 23, n. 15, p.115120, 2001.

FOLLADOR I., BITTENCOURT A., DURAN F. et al. Cutaneous protothecosis: Report of the second Brazilian case. Revista da Sociedade Brasileira de Medicina Tropical, v. 43, n. 5, p. 287-290, 2001.

FRESE, V.K.; GEDEK, B. Ein fall von protothecosis heim reh. Berliner und Münchener Tieraerztliche Wochenscrift, Berlin, v. 81; p. 171-178, 1968.

HEIKKILÄ, A. M., NOUSIAINEN, J. I., PYÖRÄLÄ, $S$. Costs of clinical mastitis with special reference to premature culling. Journal of Dairy Science, v. 95 , p. $139-150,2012$.

HODGES, R.T.; HOLLAND, J.T.S.; NEILSON, F.J.A. et al. Prototheca zopfii mastitis in a herd of dairy cow. New Zealand Veterinary Journal Palmerton North, v.33, p.108-111, 1985.

IBGE. Área territorial oficial. Resolução da Presidência do IBGE de n 5 (R.PR-5/02). 2002. IBGE - INSTITUTO BRASILEIRO DE GEOGRAFIA E ESTATÍSTICA. Estatística da produção pecuária - Dezembro de 2011, 2011 Disponível em: http://saladeimprensa.ibge.gov.br/noticias?view= noticia;id=1; busca=1;idnoticia=2241 Acesso em: 10 de abril de 2013. IBGE - INSTITUTO BRASILEIRO DE GEOGRAFIA E ESTATÍSTICA. Produção da pecuária municipal,IBGE. v.38, 2010. Disponível em: http://www.ibge.gov.br/home/estatistica/economi a/ppm/2010/ppm2010.pdf Acesso em: 10 de abril de 2013. 
JÁNOSI, S.; RÁTZ, F.; SZIGETI, G. et al. Review of the microbiological, pathological and clinical aspects of bovine mastites caused by the alga Prototheca zopfii. The Veterinary Quarterly, The Hague, v. 23, n. 2, p. 58-61, 2001.

KIRK, J.H. Diagnosis and treatment of difficult mastitis cases. Agri-Practice, [S.I.], v.12, n.2, p.15-18, 1991.

LAGNEAU, P.E. First isolation of Prototheca zopfii in bovine mastitis in Belgium. Journale de Mycologie Médicale, Paris, v.6, p.145-148, 1996.

LANGONI, H.; DOMINGUES, P.F.; FUNARI, S.R.; DIAS, H.L.T.; MORA, R.A.; ROCHA, N.S.; SFORCIN, A. Prototheca zopfii e mastite bovina: clínica e terapêutica. In: CONGRESSO BRASILEIRO DE MEDICINA VETERINÁRIA, 22., 1992, Curitiba, Anais..., Curitiba, 1992, p. 125 .

LANGONI, H.; DOMINGUES, P. F.; FUNARI, S. R. C. et al. Prototheca zopfii como agente de mastite bovina: clínica e terapêutica. Arquivo Brasileiro de Medicina Veterinária e Zootecnia, Belo Horizonte, v. 47, n. 5 p. 727-731, 1995.

LEIMANN, B.C.Q.; MONTEIRO, P.C.F.; LAZÉRA, M. et al. Protothecosis. Medical Mycology, Abingdon, v.42, n.2, p.95-106, 2004.

MELVILLE, P.A. Estudos sobre algas do gênero Prototheca isoladas de leite e de infeccões intramamárias em bovinos leiteiros. 1995. São Paulo. 94f. Dissertação (Mestrado em Microbiologia) - Instituto de Ciências Biomédicas da Universidade de São Paulo.

MELVILLE, P.A.; WATANABE, E.T.; BENITES, N.R. et al. Evaluation of the susceptibility of Prototheca zopfii to milk pasteurization. Mycopathologia, Netherlands, v.146, p.79-82, 1999.

MONOPOLI, A ACCETTURI, M.P; LOMBARDO, $G$. Cutaneous protothecosis, International Journal of Dermatology, [S.I.], v.34, n.11, p.766-767, 1995.

NATIONAL MASTITIS COUNCIL. Current concepts of bovine mastitis. 4.ed. Madison : NMC, p. 64, 1996.

PORE R.S. 1998. Prototheca, a yestlike alga. In: Kurtzman C.P.; Fell J.W. (ed). The Yeasts - A taxonomic study. New York: Elsevier, p.883-887.

PORE R.S., Barnett E.A., Barnes Jr. W.C.; Walker J.D. 1983. Prototheca ecology. Mycopathol. 81:49-62. QUINN, P. J. et al. Clinical Veterinary Microbiology, London: Wolfe, p. 648, 1994.
SILVA M.V.M.; ARAÚJO K.P.C. Mastite qualidade do leite. Revista Veterinária e Zootecnia em Minas, v. 15, p. 20-23, 2008.

SPALTON, D.E. Bovine mastitis caused by Prototheca zopfii: a cause study. The Veterinary Record, Washington, v.116, p.347-349, 1985.

TANIYAMA, H.; OKAMOTO, F.; KUROSAWA, T. et al. Disseminated protothecosis caused by Prototheca zopfii in a cow. Veterinary Pathology, [S.I.], v.31, p.123-125, 1994.

TANG, W.Y.M.; LO, K.K.; LAM, W.Y. et al. Cutaneous protothecosis: report of a case in Hong Kong. British Journal of Dermatology, [S.I.], v.133, p.479-482, 1995.

TENHAGEN, B.A.; KALBE, P.; KLÜNDER, G. et al. Individual risk factors for Prototheca mastitis in cattle. Deutsch Tierärztliche Wochenschrift, Berlin, v.106, n9, p.376-380, 1999.

THIELE D.; BERGMANN A. Mini-review: Protothecosis in human medicine. Int. J. Hyg. Environ. Health, v. 204, p. 297-302, 2002.

TOZZETI, D. S. BATAIER, M. B. N.; ALMEIDA, L. R. Prevenção, controle e tratamento das mastites bovinas - Revisão de literatura. Revista Científica Eletrônica de Medicina Veterinária, Garça, v. 6, n. 10, p. 1-7, jan. 2008.

VAZ A.K., CARNEIRO D.M.V.F, DICK W. et al. Mastite bovina por Prototheca spp. em Santa Catarina: relato de caso. Revista de Ciências Agroveterinárias, v. 4, p. 72-75, 2005

YAMAMURA, A. A. M.; MÜLLER, E. E. Fatores predisponentes associados à mastite bovina causada por Prototheca zopfii. 2006. Londrina. 69f. Tese (Doutorado em Ciência Animal) Universidade Estadual de Londrina. 